\title{
Determination of Glycerol in Wine by Amperometric Flow Injection Analysis with an Immobilized Glycerol Dehydrogenase Reactor
}

\author{
Kiyoshi Matsumoto, Hiroaki Matsubara, Masashi Hamada, \\ Toyohiko Dor* and Yutaka OsAJIMA \\ Department of Food Science and Technology, Faculty of Agriculture, Kyushu University 46-09, \\ Hakozaki, Higashi-ku, Fukuoka 812, Japan \\ * Engineering Research Center, Morinaga Milk Industry Co., Ltd., 4-515, \\ Tateno, Higashiyamato, Tokyo 189, Japan
}

Received October 22, 1990

\begin{abstract}
A glycerol sensor, in which glycerol dehydrogenase was immobilized on Amino-Cellulofine, was developed for the continuous determination of glycerol in wine. NADH produced by the enzyme reaction was monitored amperometrically with a platinum electrode. A sandwich method was used for sample injection as an effective mixing mode of NAD and sample. A typical calibration curve showed a slightly convex curve between response and glycerol concentration (0.1-2 mm; $\left.1.8 \times 10^{-8}-3.6 \times 10^{-7} \mathrm{~mol}\right)$. The relative standard deviation for ten measurements of $9 \times 10^{-8} \mathrm{~mol}$ glycerol was $0.5 \%$. The proposed method was used for wine analysis and was compared with an F-kit (enzymatic, spectrophotometric) method.
\end{abstract}

Glycerol in wine is one of the important components along with alcohol, organic acids, and sugars. Glycerol is produced as a by-product of alcoholic fermentation from sugar and is thought to be a quality factor of wine. So, it is important to determine glycerol in wine at control laboratories of wineries. Many methods have been reported for the determination of glycerol in wine ${ }^{1-4)}$ but only. few are enzymatic.

Most of the enzymatic methods for glycerol are concerned with triglyceride determination in biological samples, in which glycerol is liberated by enzymatic hydrolysis or saponification. The methods have been based on a series of enzymatic reactions with glycerol kinase, pyruvate kinase, and lactate dehydrogenase, or glycerol kinase and glycero-3phosphate dehydrogenase. ${ }^{5-8)}$ Commercial kits are available for this method. ${ }^{7)}$

Another method uses glycerol dehydrogenase $(\mathrm{GDH})$, which catalyzes the reaction shown in eq. 1.

$$
\begin{aligned}
& \text { Glycerol }+\mathrm{NAD}^{+} \stackrel{\mathrm{GDH}}{\longrightarrow} \\
& \text { Dihydroxyacetone }+\mathrm{NADH}+\mathrm{H}^{+}
\end{aligned}
$$

The NADH produced can be monitored by spectrophotometry, ${ }^{9)}$ fluorimetry, ${ }^{10-13)}$ and amperometry. ${ }^{14,15)}$

The combination of an immobilized enzyme reactor and the flow injection analytical method constitutes a powerful technique for the determination of glycerol. The requirement of the co-enzyme NAD for the enzyme reaction, however, will raise the running cost of the method using FIA methodology.

This paper describes a study in which an immobilized glycerol dehydrogenase reactor was used to determine glycerol in wine in a flowing stream. The produced NADH is monitored amperometrically. The effective mixing mode of NAD and glycerol is demonstrated.

\section{Materials and Methods}

Reagents. Glycerol dehydrogenase (GDH, EC 1.1.1.6, from Enterobactor aerogenes) was obtained from Boehringer Mannheim GmbH. Glycerol (above 98.5\%) was purchased from Ishizu Pharmaceutical Co., Ltd. (Osaka, Japan) and used as a glycerol standard. Amino-Cellulofine was purchased from Seikagaku Kogyo Co. (Tokyo, Japan) 
Sodium cyanoborohydride and glutaraldehyde $(25 \%)$ were obtained from Nacalai Tesque Inc. (Kyoto, Japan). All other chemicals were of reagent grade and were used without further purification.

Preparation of GDH immobilized on Amino-Cellulofine. Amino-Cellulofine (wet weight $0.3 \mathrm{~g}$, dry weight about $0.03 \mathrm{~g}$ ) was washed thoroughly with distilled water and $0.2 \mathrm{M}$ carbonate buffer ( $\mathrm{pH} 10$ ) on a sintered glass filter (G-3). The Cellulofine thus purified was used as a support. The support was mixed with $0.2 \mathrm{M}$ carbonate buffer $(\mathrm{pH}$ 10) containing $5 \%$ glutaraldehyde for $2 \mathrm{hr}$ at $20^{\circ} \mathrm{C}$ while shaking. The resulting precipitate was separated from the solution by filtration (sintered glass filter, G-3) and washed thoroughly with distilled water and $0.05 \mathrm{M}$ phosphate buffer $(\mathrm{pH} 8)$. By these procedures, aldehyde functionalities were introduced at the terminal $\mathrm{NH}_{2}$ groups of the support. The support thus treated was put into $1 \mathrm{ml}$ of $0.05 \mathrm{M}$ phosphate buffer ( $\mathrm{pH} 8$, coupling solution) containing glycerol dehydrogenase $(10 \mathrm{U})$ and then allowed to react for $30 \mathrm{~min}$ at $5^{\circ} \mathrm{C}$ while being shaken intermittently. The support obtained was reduced with about $2 \mathrm{mg}$ of sodium cyanoborohydride for $12 \mathrm{hr}$ at $5^{\circ} \mathrm{C}$ and then washed thoroughly with $0.05 \mathrm{M}$ phosphate buffer $(\mathrm{pH} 8)$ containing $0.5 \mathrm{M} \mathrm{NaCl}$ (washing solution) and the coupling solution in turn. The residual functionalities on the GDH immobilized Cellulofine were then blocked with $2 \mathrm{ml}$ of $15 \mathrm{mg} / \mathrm{ml}$ glycine solution by standing for $2 \mathrm{hr}$ at $20^{\circ} \mathrm{C}$, and the GDH immobilized Cellulofine was separated by filtration and was successively washed with the washing solution and the coupling solution. The GDH immobilized Cellulofine was packed in a glass tube $(2 \mathrm{~mm}$ i.d. $\times 10 \mathrm{~cm})$ and the reactor was filled with the coupling solution and was stored at $5^{\circ} \mathrm{C}$

Flow system. A schematic diagram of the flow system is shown in Fig. 1. The working solution (carrier solution) in a reservoir was propelled by a micro-tube pump (Tokyo Rikakikai Co., Ltd.) through an air-damper, a sample injection valve (16-way switching valve, Hitachi K-1600),

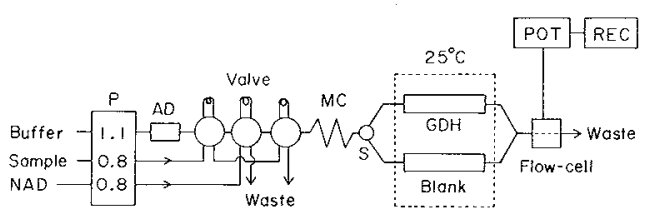

Fig. 1. Schematic Diagram of the Flow Injection Analytical System.

P, microtube pump; AD, air-damper; Valve, 16-way switching valve; $\mathrm{MC}$, mixing coil ( $1 \mathrm{~mm}$ i.d., $40 \mathrm{~cm}$ ); $\mathrm{GDH}$, immobilized GDH column; Blank, blank column; S, 3-way switching valve; POT, potentiostat; REC, recorder; Buffer, $0.125 \mathrm{M}$ carbonate buffer containing $30 \mathrm{~mm}$ ammonium sulfate $(\mathrm{pH} \mathrm{10})$. The flow rates are indicated (in $\mathrm{ml} / \mathrm{min}$ ) in the pump $(\mathrm{P})$. and an immobilized GDH reactor and then was transported to an electrochemical flow-through cell and finally to a waste tank. The main flow line was divided into two flow lines at the position $S$ in Fig. 1 by a 3-way switching valve. The 3 -way switching valve was properly switched to an immobilized GDH column for a glycerol signal intake or to a blank column for a blank value intake. The blank column was the same size as the enzyme column and contained Amino-Cellulofine without the immobilized enzyme. The sample flow system consisted of another micro-tube pump connected to the same sample injection valve (16-way switching valve) equipped with sample loops. The sample and co-enzyme NAD were injected by a sandwich method. The details of the injection method are mentioned in the section of Results and Discussion. The temperature of the immobilized $\mathrm{GDH}$ reactor was controlled at $25^{\circ} \mathrm{C}$. The design of the flow-through cell was mentioned previously. ${ }^{16}$ Amperometric measurements were made with a laboratory-made multichannel potentiostat, which was described previously. ${ }^{17)}$ The potential was set to be $+0.75 \mathrm{~V}$ vs. $\mathrm{Ag} / \mathrm{AgCl}$. Other instrument in the system were the same as those in our previous work. ${ }^{18 \text {; }}$

F-kit method. An F-kit (glycerol, test for the enzymatic determination of glycerol in foodstuffs, No. 148270) was purchased from Boehringer Mannheim GmbH. The procedure was done according to the manufacturer's manual. The method uses the following reactions. ${ }^{19)}$

$$
\begin{aligned}
& \text { Glycerol + ATP } \\
& \underset{\text { klycerol }}{\stackrel{\text { kinase }}{\longrightarrow}} \text { ADP + Glycerol-3-phosphate }
\end{aligned}
$$

$$
\begin{aligned}
& \text { ADP + Phosphoenolpyruvate } \\
& \underset{\text { kinase }}{\stackrel{\text { pyruvate }}{\longrightarrow}} \mathrm{ATP}+\text { Pyruvate }
\end{aligned}
$$

$$
\begin{aligned}
& \text { Pruvate }+\mathrm{NADH}+\mathrm{H}^{+} \\
& \underset{\text { dehydrogenase }}{\stackrel{\text { lactate }}{\longrightarrow} \text { Lactate }+\mathrm{NAD}^{+}}
\end{aligned}
$$

The amount of glycerol present is proportional to the decrease in the absorbance of $\mathrm{NADH}$ at $340 \mathrm{~nm}$.

\section{Results and Discussion}

\section{Comparison of carrier solution}

Two kinds of buffer were investigated for the sensor response of the immobilized GDH reactor. Carbonate buffer showed about 1.5 -fold greater response than pyrophosphate buffer when the same concentration $(0.1 \mathrm{M})$ and the same $\mathrm{pH}(10)$ were used. The effects of ammonium ion and potassium ion on the 
response of the immobilized GDH reactor were investigated because of reports in the literature that GDH from Aerobactor aerogenes was activated by monovalent cations such as $\mathrm{NH}_{4}{ }^{+}, \mathrm{Tl}^{+}, \mathrm{K}^{+}$, and $\mathrm{Rb}^{+}{ }^{20,21\}}$ When ammonium sulfate $(30 \mathrm{~mm})$ and potassium sulfate $(30 \mathrm{~mm})$ were added to $0.125 \mathrm{M}$ carbonate buffer and the pHs of the solutions were adjusted to 10 , the responses of the immobilized GDH reactor were magnified about 10 -fold compared with that from the same buffer containing no activating monovalent cation. Though the response enhancement by potassium ion was nearly equal with that by ammonium ion, ammonium ion was superior to potassium ion with regard to the stability improvement of the immobilized GDH reactor. The effects of $\mathrm{pH}$ on the response were studied from $\mathrm{pH} 9$ to 11 , using $0.125 \mathrm{M}$ carbonate buffer. The maximum response was obtained at $\mathrm{pH} 10$ 10.5. Carbonate buffer $(0.125 \mathrm{M}, \mathrm{pH} 10)$ containing $30 \mathrm{~mm}$ ammonium sulfate was used as a working solution.

\section{Mixing mode of NAD and glycerol}

Using an NAD-dependent dehydrogenase system for substrate measurement requires the addition of NAD. The addition of NAD in the carrier solution has been widely used. This pre-mixing method, however, has an economical defect, that too much NAD was consumed. In this experiment, the mixing mode of NAD and glycerol was investigated for the economical running of the system and the efficiency of the enzyme reaction. Three mixing modes were compared; pre-mixing, sandwich, and open sandwich methods. ${ }^{22)}$ NAD was mixed previously with the sample (glycerol) for the pre-mixing method. For the sandwich method, NAD was sandwiched by two sample zones. For the open sandwich method, NAD and sample were injected in zones next to each other. The Hitachi 16-way switching valve was useful for these injections, allowing a one-touch operation. The schematic arrangements of valve connection and those of NAD and sample zones in the tube are illustrated in Fig. 2. The mixing efficiency of the three mixing methods

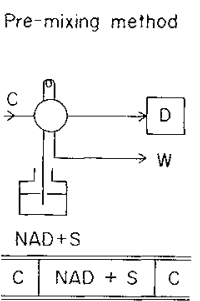

Sand wich method

Open sandwich method

Fig. 2. Schematic Illustration of Mixing Mode of NAD and Sample.

C, carrier solution; S, sample solution; D, detector; W, waste.
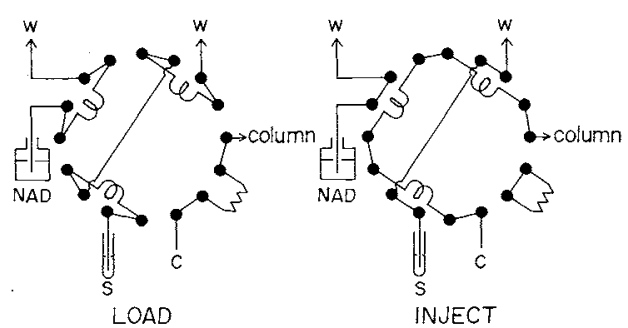

Fig. 3. Arrangement of 16-Way Switching Valve for Sandwich Method at Load and Injection Position.

$\mathrm{C}$, carrier solution; $\mathrm{S}$, sample solution.

was as follows: pre-mixing $(100 \%)$, sandwich $(99 \%)$, and open sandwich $(91 \%)$, when the same amount and the same concentration of NAD $(90 \mu \mathrm{l}, 10 \mathrm{~mm})$ and glycerol $(180 \mu \mathrm{l}$, $1.0 \mathrm{~mm})$ were injected. The pre-mixing method produced the largest response, but the method has defects in that NAD will react with reducing substances in the sample and yet an excess of NAD is required. The sandwich method produced a higher response and higher reproducibility than the open sandwich method, which suggests higher and reliable mixing efficiency of NAD and sample. The sandwich method was adopted in the subsequent experiment in consideration of economy, simplicity, reproducibility, and rapidity. For details, Fig. 3 shows the tube connections of the 16-way switching valve for the sandwich method at the load and injection position.

\section{Applied potential}

To identify the optimum applied potential, the effects of the applied potential on the electrode response were investigated using 
$10 \mathrm{~mm}$ NAD and $0.5 \mathrm{~mm}$ glycerol. The applied potential was changed from $+0.6 \mathrm{~V}$ to $+0.8 \mathrm{~V}$ vs. $\mathrm{Ag} / \mathrm{AgCl}$ and the oxidation current was measured. The electrode response increased with increasing potential and reached a plateau at about $+0.75 \mathrm{~V}$ vs. $\mathrm{Ag} / \mathrm{AgCl}$. In general, a high applied potential tends to produce interfering currents, because of the oxidation of other components in the sample. Therefore, it is desirable to select the smallet possible potential for the oxidation of NADH. The response was small in this system, because NADH produced from the enzyme reaction was monitored. The applied potential of $+0.75 \mathrm{~V}$ was used in the subsequent experiment.

\section{$N A D$ concentration and $G D H$ amount}

The effects of NAD concentration on the response of the immobilized GDH reactor are shown in Fig. 4. The response increased with increasing NAD concentration and leveled off around $10 \mathrm{~mm}$. In this measuring system, NAD was thrown away at each run, and it is desirable, therefore, to save consumed NAD. The concentration of $10 \mathrm{~mm}$ NAD was adopted in consideration of relatively large response and low cost ( 2 yen/run for NAD consumption).

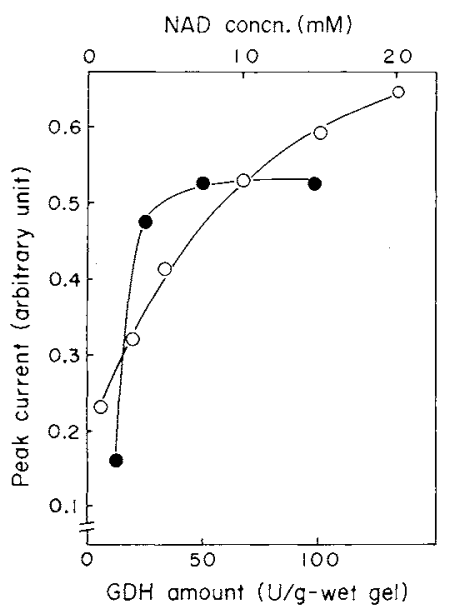

Fig. 4. Effects of NAD Concentration (O) and GDH Amount (1) on the Sensor Responses.

GDH amount was $300 \mathrm{U} / \mathrm{g}$-wet gel in plots of peak current vs. NAD concentration. NAD concentration was $10 \mathrm{~mm}$ $(180 \mu \mathrm{l})$ in plots of peak current vs. GDH amount.
The effects of the amount of GDH on the response of the reactor were also investigated and are shown in Fig. 4. The response rapidly increased up to $33 \mathrm{U} / \mathrm{g}$-wet gel and became nearly constant above this amount.

\section{Flow rate}

Figure 5 shows the effects of the flow rate on the sensor response and the baseline reversion time ( $95 \%$ reversion). The response rapidly increased with increasing flow rate up to $1.1 \mathrm{ml} / \mathrm{min}$, then gradually decreased. The time for baseline reversion was rapidly decreased with increasing flow rate up to $1.3 \mathrm{ml} / \mathrm{min}$, and then decreased gradually. A

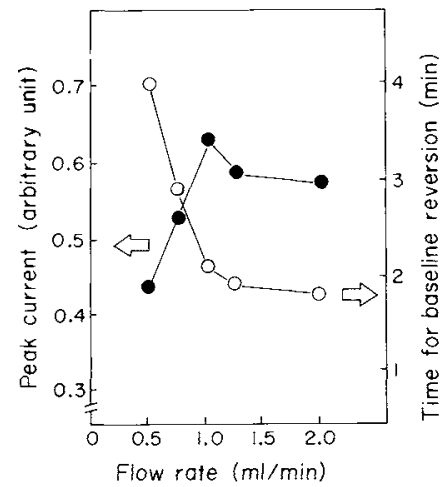

Fig. 5. Effect of the Flow Rate on the Sensor Responses (C) and Baseline Reversion Time (O).

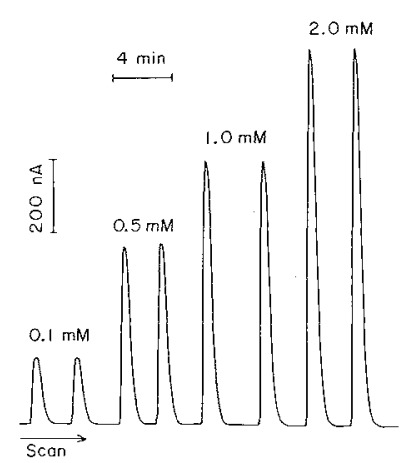

Fig. 6. Typical FIA Responses for Glycerol.

Flow rate, $1.1 \mathrm{ml} / \mathrm{min}$; Applied potential, $+0.75 \mathrm{~V}$ vs. $\mathrm{Ag} / \mathrm{AgCl}$; Mixing mode, sandwich method; Sample amount, $180 \mu \mathrm{l}$; NAD amount, $10 \mathrm{~mm}(17 \mu 1) ; \mathrm{GDH}$ amount, $33 \mathrm{U} / \mathrm{g}$-wet gel; Carrier solution, $0.125 \mathrm{M}$ carbonate buffer containing $30 \mathrm{~mm}$ ammonium sulfate $(\mathrm{pH}$ $10)$. 
flow rate of $1.1 \mathrm{ml} / \mathrm{min}$ was used in this experiment, considering the maximum response and the relatively short sample output time.

Calibration, reproducibility and long-term stability

A typical calibration curve showed a slightly convex curve between response and glycerol concentration $\left(0.1-2 \mathrm{~mm} ; 1.8 \times 10^{-8}-3.6 \times 10^{-7}\right.$ $\mathrm{mol}$ ). Figure 6 shows the typical response curves under the optimum conditions of the flow system. The current increased rapidly just after injection of sample and NAD, and returned to baseline within $2 \mathrm{~min}$. The relative standard deviation for ten measurements at $0.5 \mathrm{~mm}\left(9 \times 10^{-8} \mathrm{~mol}\right)$ level was $0.5 \%$. The response of the immobilized $\mathrm{GDH}$ reactor increased gradually day by day to about 2 -fold of the initial value for 10 days and the value was maintained for 26 days after the arrival of the maximum, and then gradually decreased. After 60 days, the response decreased about $50 \%$ of the maximum. In this experiment, the immobilized GDH packed in a glass tube was used for about 10 injections of standard glycerol $(0.5 \mathrm{~mm})$ every two days, and, when not in use, stored at $5^{\circ} \mathrm{C}$ in the working solution.

\section{Application to wine analysis}

Table I shows the results for the determination of glycerol in wine using of this system.

Table I. Comparison of the Present Method (FIA) WITH THE F-KIT (ENZYMATIC) METHOD FOR THE DETERMination OF GLyCEROL IN White Wine

\begin{tabular}{cccc}
\cline { 3 - 3 } Sample & $\begin{array}{c}\text { Present } \\
\text { Method } \\
(\text { FIA }) \\
(\mathrm{A})\end{array}$ & $\begin{array}{c}\text { F-kit } \\
\text { method } \\
(\mathrm{B})\end{array}$ & $\begin{array}{c}\text { Bias } \\
(\mathrm{A}-\mathrm{B}) \\
(\%)\end{array}$ \\
\hline White 1 & 0.58 & 0.56 & 0.02 \\
White 2 & 0.48 & 0.45 & 0.03 \\
White 3 & 0.58 & 0.61 & -0.03 \\
White 4 & 0.55 & 0.53 & 0.02 \\
White 5 & 0.53 & 0.54 & -0.01 \\
\hline
\end{tabular}

Wine samples were diluted 100 -fold and injected. The small responses from the blank column were substracted from those from the GDH reactor. These results are compared to those obtained by the F-kit method. As shown in Table I, the values measured with this FIA coincided relatively well with those of the F-kit method. This method is useful for simple and rapid measurement of glycerol in wine.

\section{References}

1) T. Shinohara and M. Watanabe, J. Brew. Soc. Jpn., 71, 888 (1976).

2) Y. Shimazu, M. Uehara and M. Watanabe, J. Brew. Soc. Jpn., 75, 327 (1980).

3) C. Otoguro, S. Ogino and M. Watanabe, J. Brew. Soc. Jpn., 78, 214 (1983).

4) C. Otoguro, S. Ogino and M. Watanabe, J. Brew. Soc. Jpn., 78, 220 (1983).

5) G. Bucolc and H. David, Clin. Chem., 19, 476 (1973)

6) A. R. MacRae, Clin. Biochem., 10, 16 (1977).

7) G. Lehnus and L. Smith, Clin. Chem., 24, 27 (1978).

8) P. Schwandt, W. O. Richter and N. Kriegisch, Clin. Chem., 27, 512 (1981).

9) M. Masoom and P. J. Worsfold, Anal. Chim. Acta, 188, 181 (1986).

10) M. G. Gore, Anal. Biochem., 75, 604 (1976).

11) M. M. Fishman, Anal. Chem., 50, 206R (1978).

12) N. Kiba, K. Goto and M. Furusawa, Anal. Chim. Acta, 185, 287 (1986).

13) S. Yonezawa, F. Morishita and T. Kojima, Anal. Sci. (Tokyo), 3, 553 (1987).

14) A. S. Attiyat and G. D. Christian, Anal. Chim. Acta, 106, 225 (1979)

15) T. Fonong, Anal. Lett., 20, 783 (1987).

16) K. Matsumoto, O. Hamada, H. Ukeda and Y. Osajima, Anal. Chem., 58, 2732 (1986).

17) K. Matsumoto, H. Matsubara, M. Hamada, H. Ukeda and Y. Osajima, Anal. Chem., 60, 147 (1988).

18) K. Matsumoto, H. Matsubara, M. Hamada, H. Ukeda and Y. Osajima, J. Biotechnol, 14, 115 (1990).

19) O. H. Wieland, in "Methods of Enzymatic Analysis," 3rd Ed., Vol. 6, ed. by H. U. Bergmeyer, VCH Verlargsgesellschaft $\mathrm{mbH}$, Weinheim, 1984, pp. 504-510.

20) E. C. Lin and B. Magasanik, J. Biol. Chem., 235, $1820(1960)$

21) W. G. Mcgregor, J. Phillips and C. H. Suelter, J. Biol. Chem., 249, 3132 (1974).

22) J. Toei, Anal. Lett., 20, 1951 (1987). 